\title{
Finger blood pressure and rewarming rate for screening and diagnosis of Raynaud's phenomenon in workers exposed to vibration
}

\author{
H Virokannas, H Rintamäki
}

\begin{abstract}
Both the finger systolic blood pressure (FSP) and the rewarming test of finger skin are measures of circulation in the finger; the first reflects the vasoconstriction phase and the second the vasodilatation phase. The combinations of the specificity and the sensitivity of these methods were evaluated by a receiver operating characteristic curve (ROC). The material included 37 vibration-induced white finger (VWF) cases, five primary Raynaud's cases, and 37 controls. The specificity of the FSP test was high with regard to the anamnesis of white finger and the test was useful for the diagnosis of Raynaud's phenomenon, but the sensitivity was too low for screening. The rewarming test was useful for screening primary Raynaud's cases and possibly for screening disorders in peripheral vasodilatative function. The connections between the rewarming test and VWF are not clear and according to the present study the rewarming test was not suitable for screening VWF.
\end{abstract}

An exposure to hand-arm vibration can cause peripheral vascular disorders, but the measurement of these functional changes and damage has been difficult. For screening, the test should be highly sensitive, and for diagnostic purposes good specificity is important. The rewarming temperature of finger skin after cold water immersion has been recommended as a screening test for vibration-induced white finger (VWF)-for example, in Japan ${ }^{1}$ - but the method is not generally accepted for screening. It is a simple and low cost test, easy to perform even in field conditions, and the rewarming indices have a statis-

Oulu Regional Institute of Occupational Health, PO Box 451, SF-90101 Oulu, Finland

H Virokannas, H Rintamäki

Department of Public Health Science, University of Oulu, Oulu, Finland

H Virokannas tical connection to VWF. ${ }^{23}$ The test has been considered useful on a group basis, but less so in the evaluation of individual subjects. ${ }^{4}$ Many variations of the test have been presented and the evaluation of the results has been variable. ${ }^{1-3}$

The measurement of finger systolic blood pressure (FSP) has been reported to be a reliable test to diagnose Raynaud's phenomenon. ${ }^{56}$ The plethysmographic method developed by Nielsen and Lassen ${ }^{7}$ is well documented and stated to be specific and quite sensitive for digital vasospasm. It gives objective findings for the closure of digital main arteries during cold exposure.

The aim of the present study was to compare the plethysmographic method of FSP measurement and the rewarming rate of finger skin after local cooling, and to evaluate the suitability of these two tests for screening and diagnosis of Raynaud's phenomenon in workers exposed to vibration.

\section{Material and methods \\ SUBJECTS}

The subjects were divided into three groups according to their exposure to hand-arm vibration and the anamnesis of white finger: (1) the VWF group comprising 21 reindeer herders exposed to vibration by snowmobiles and 16 railroad workers exposed mainly by track repairing machines (pneumatic hammers); (2) the primary Raynaud's (PR) group containing five railroad workers who had suffered their first attack of white finger before exposure to vibration and when they were less than 25 years old; (3) the control group consisting of 37 men who had not suffered an attack of white finger; the 37 men comprised 20 railroad workers who were exposed to hand vibration and 17 indoor workers without exposure to vibration (table 1).

Anamnesis data on the exposure to vibration and the hand symptoms were collected with the aid of a questionnaire and checked at an interview. Clinical examinations, cold water immersion tests for an evaluation of the rewarming rate, and measurement of finger systolic blood pressure were carried out during late winter and early spring. 
Table 1 Age, lifetime exposure to vibration (mean (SD)), and percentage of current smokers in the study groups

\begin{tabular}{lllll}
\hline Group & No of subjects & Age $(y)$ & Exposure to vibration $(h)$ & Smoking $(\%)$ \\
\hline VWF & 37 & $46 \cdot 8(9 \cdot 1)$ & $13900(6600)$ & 70 \\
PR & 5 & $29 \cdot 6(7 \cdot 2)$ & $2700(1800)$ & 40 \\
Control & 37 & $38 \cdot 7(9 \cdot 8)$ & $3900(4600)$ & 43 \\
\hline
\end{tabular}

\section{FINGER SYSTOLIC BLOOD PRESSURE}

The subjects were examined in a supine position after a 20 minute rest at room temperature $\left(20-23^{\circ} \mathrm{C}\right)$. They wore no clothing on the upper body and arms. Brachial blood pressure was determined with an automatic blood pressure measuring machine (Dinamap 1845P) and standard cuff, and FSP with a plethysmograph (Digitmatic DM 2000) using a digit cooling unit according to the method suggested by Nielsen and Lassen. ${ }^{7}$ Cooling of the middle phalanx of the test finger was performed with a water cuff at 30 , 15 , and $10^{\circ} \mathrm{C}$ during five minutes of ischaemia. The suprasystolic pressure $(210-230 \mathrm{~mm} \mathrm{Hg})$ was generated with cuffs placed on the proximal phalanx of the test finger and the reference finger. The test finger was the middle finger of the hand in which the most severe attacks of white finger had occurred and the reference was the corresponding finger of the contralateral hand. The FSP during cooling expressed as a percentage of the basic pressure at $30^{\circ} \mathrm{C}$ and corrected for the changes in the systemic pressure $(\mathrm{FSP} \%)^{8}$ was used as an indicator. Finger systolic blood pressure at $30^{\circ} \mathrm{C}$ (FSP 30) divided by brachial systolic blood pressure (BSP) (FSP/BSP) was used to indicate the obstruction of circulation in the hand before local cooling.

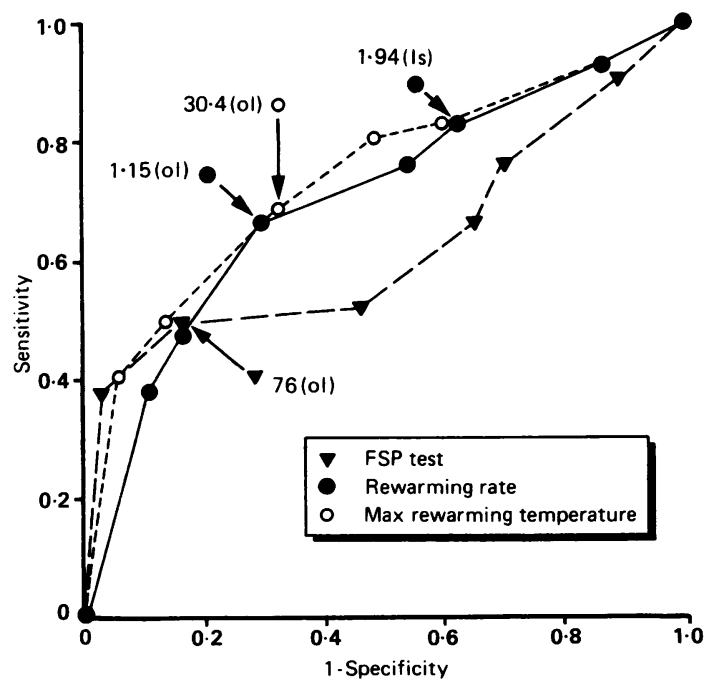

Figure 1 Receiver operating characteristic curve (ROC) with regard to anamnesis of Raynaud's phenomenon. Values of the optimal limits (ol) and the recommended limit for screening (ls) are shown.
REWARMING OF FINGER SKIN TEMPERATURE

In the rewarming test cold provocation was provided by stirred water at approximately $10^{\circ} \mathrm{C}$. The hand was immersed up to the wrist for 10 minutes. After immersion the hand was dried by light towelling and the temperatures of finger skin were recorded for 20 minutes in a room temperature. During the test the clothed (insulation $0.7 \mathrm{clo}$ ) subjects were in a sitting position. The range of temperature of the water was $9 \cdot 4-10 \cdot 6^{\circ} \mathrm{C}$ and the temperature in the room was $20-23^{\circ} \mathrm{C}$. For indicators of rewarming the maximum finger skin temperature reached after immersion and the rewarming rate between $10 \%$ and $90 \%$ of maximal rewarming temperature on the test finger (the same as in the FSP test) were chosen. Skin temperatures were measured every 30 seconds with a data logger and computer by YSI 400 series probes fixed with waterproof adhesive tape at the volar side of the distal phalanx of the fingers.

\section{CALCULATIONS AND STATISTICS}

The combinations of the specificity and the sensitivity of the studied methods with regard to Raynaud's phenomenon were evaluated by receiver operating characteristic curve $(\mathrm{ROC})^{9}$ (fig 1). When the false negative and false positive results were considered to be equally harmful the corresponding value of the studied method evaluated by ROC was called the optimal limit. Linear regression and Student's $t$ test were used in the statistical analysis.

\section{Results}

FINGER SYSTOLIC BLOOD PRESSURE

The FSPs and the FSP $\%$ s at 15 (FSP\%15) and $10^{\circ} \mathrm{C}$ (FSP\%10) were significantly lower in the VWF group than in the control group. The VWF group also had a lower blood pressure relation between finger and brachial arteries than the controls. The PRs had the lowest values in every index (table 2). The FSP\% 10 had a slight negative linear correlation with the time of the exposure to vibration ( $r=-0.20, p<0.07$ ), whereas age and smoking had no significant effect on it.

The optimal limit of the FSP\% evaluated with ROC in regard to Raynaud's phenomenon was $76 \%$ in the present study (fig 1), which was used as a limit of normal values. Consequently, the specificity of the test to the anamnesis of white finger was as high as $84 \%$ (table 3). The FSP\% was lower than this limit among $46 \%$ of the VWF cases, $16 \%$ of the controls, 
Table 2 Finger systolic blood pressure (FSP) test

\begin{tabular}{|c|c|c|c|}
\hline & $V W F(n=37)$ & Control $(n=37)$ & $P R(n=5)$ \\
\hline $\begin{array}{l}\text { BSP }(\mathrm{mmHg}) \\
\text { FSP30 }(\mathrm{mmHg}) \\
\text { FSP15 }(\mathrm{mmHg}) \\
\text { FSP10 }(\mathrm{mmHg}) \\
\text { FSP } \% 15 \\
\text { FSP } \% 10 \\
\text { FSP } / \text { BSP } \% \\
\text { Rewarming } \operatorname{rate}\left({ }^{\circ} \mathrm{C} / \mathrm{min}\right) \\
\text { Rewarming } \operatorname{Tmax}\left({ }^{\circ} \mathrm{C}\right)\end{array}$ & $\begin{array}{l}135(18) \\
122(19) \\
95(48)^{\star} \\
83(57)^{\star \star} \\
75(37)^{\star} \\
63(43)^{\star \star \star} \\
91(11)^{\star} \\
1 \cdot 13(0 \cdot 86)^{\star \star} \\
25 \cdot 2(7 \cdot 40)^{\star \star \star}\end{array}$ & $\begin{array}{l}130(13) \\
125(14) \\
114(22) \\
114(19) \\
90(14) \\
90(10) \\
97(10) \\
1.69(0.88) \\
30.3(4 \cdot 80)\end{array}$ & $\begin{array}{l}129(5) \\
102(11)^{\star \star} \\
50(50)^{\star} \\
42(58)^{\star} \\
43(43) \\
33(47)^{\star} \\
79(10)^{\star \star \star} \\
0 \cdot 56(0.31)^{\star \star \star} \\
21 \cdot 1(6 \cdot 20)^{\star \star}\end{array}$ \\
\hline
\end{tabular}

${ }^{\star} \mathrm{p}<0.05 ;{ }^{\star \star} \mathrm{p}<0.01 ; \mathrm{p}<0.001$ ( $t$ test, compared with controls). All values are mean (SD).

and $80 \%$ of the PRs. If the recommended limit: of $60 \%{ }^{6}{ }^{10}$ had been used, the specificity of the test would have been very high (table 3 ).

\section{REWARMING OF FINGER SKIN TEMPERATURE}

The VWF group had significantly lower rewarming indices than the control group and the PRs had the smallest values as judged by all indices (table 2 ). The rewarming indices had a strong linear correlation with each other $(r=0.82, p<0.0001)$ and they had a slight negative correlation with the exposure to vibration $(r=-0.20, p>0.07)$, but age and smoking were not related to them.

The optimal limit of the rewarming rate evaluated by $R O C$ was $1.15^{\circ} \mathrm{C} / \mathrm{min}$ and the maximum rewarming temperature $30.4^{\circ} \mathrm{C}$ (fig 1 ). The sensitivity and the specificity of both indices were close to $70 \%$ (table 3 ). In this study the rewarming rate was regarded as slow when it was slower than $1 \cdot 15^{\circ} \mathrm{C} / \mathrm{min}$. According to this classification $62 \%$ of the VWF cases, $30 \%$ of the controls, and all PR cases had a slow rewarming rate. If the test is used for screening and the sensitivity should be high, the recommended limit according to the ROC was $1.94^{\circ} \mathrm{C} / \mathrm{min}$ (fig 1 ).

\section{COMPARISON OF THE TESTS}

In the entire material, only a small positive correlation was found between the FSP\% and the rewarming rate $(r=0.26, p>0.02)$. Forty seven per cent of all subjects had the opposite results in these two tests (table 4). In the VWF group the difference in the test results was greater than in the controls. In the control group $54 \%$ of the subjects had normal results and only one subject had findings in each test (table
4). In the PR group nearly all had pathological results in each test.

The FSP/BSP relation was significantly lower in the group in which the FSP\% was decreased (mean 89 (SD 11) \%) compared with the group in which the FSP\% was normal (95 (SD 11) \%; p < 0.03). The relation had no connection with the rewarming rate.

If the subjects had been screened first using the rewarming rate (with the limit of $1.94^{\circ} \mathrm{C} / \mathrm{min}$ ) and then studied using the FSP\% (with the limit of $76 \%$ ), the combination would have had a sensitivity of $43 \%$ and a specificity of $92 \%$.

\section{Discussion}

Both the FSP and the rewarming of finger skin temperature reflect the state of blood flow in the finger, but the FSP test measures the strength of vasoconstriction in digital main arteries, whereas the rewarming test measures the function of vasodilatation taking skin circulation also into account (fig 2). Despite this fundamental dissimilarity between the tests, the rewarming rate was slower and the FSP correspondingly decreased more among the white finger cases than the controls, in accordance with many other studies. ${ }^{2358} \mathrm{~A}$ more detailed analysis by ROC, however, showed new differences between these tests. As an end result, the FSP test seemed to be appropriate for diagnosing Raynaud's phenomena, whereas the rewarming test seemed to be useful for the screening of primary Raynaud's cases but not for screening VWF. In accordance with previous studies, ${ }^{28}$ the present results did not show

Table 3 Sensitivity and specificity of FSP test and rewarming test with regard to the anamnesis of white finger

\begin{tabular}{|c|c|c|c|}
\hline Indicator & Limit & Sensitivity (\%) & Specificity (\%) \\
\hline $\begin{array}{l}\text { FSP\% } \\
\text { Rewarming rate }\left({ }^{\circ} \mathrm{C} / \mathrm{min}\right) \\
\text { Rewarming } T \max \left({ }^{\circ} \mathrm{C}\right)\end{array}$ & $\begin{array}{l}76 \\
60 \\
1 \cdot 15 \\
1.94 \\
30 \cdot 4\end{array}$ & $\begin{array}{l}50 \\
38 \\
67 \\
83 \\
69\end{array}$ & $\begin{array}{l}84 \\
97 \\
70 \\
38 \\
68\end{array}$ \\
\hline
\end{tabular}


Table 4 Distribution of the subjects according to FSP and rewarming tests

\begin{tabular}{|c|c|c|c|c|}
\hline \multirow{2}{*}{$\frac{\text { Rewarming rate }}{\text { Normal }\left(>1 \cdot 14^{\circ} \mathrm{C} / \mathrm{min}\right)}$} & \multicolumn{4}{|l|}{$F S P \%$} \\
\hline & \multicolumn{2}{|c|}{ Normal $(>75 \%)$} & \multicolumn{2}{|c|}{ Decreased $(<76 \%)$} \\
\hline $\begin{array}{l}\text { Normal }\left(>1 \cdot 14^{\circ} \mathrm{C} / \mathrm{min}\right) \\
\text { Slow }\left(<1 \cdot 15^{\circ} \mathrm{C} / \mathrm{min}\right) \\
\text { All }\end{array}$ & $\begin{array}{l}\text { All } \\
\text { VWF } \\
\text { Cont } \\
\text { All } \\
\text { VWF } \\
\text { Cont }\end{array}$ & $\begin{array}{l}\mathbf{n}=27(34 \%) \\
\mathbf{n}=7(19 \%) \\
\mathbf{n}=20(54 \%) \\
\mathbf{n}=25(32 \%) \\
\mathbf{n}=13(35 \%) \\
\mathbf{n}=11(30 \%) \\
\mathbf{n}=52(66 \%)\end{array}$ & $\begin{array}{l}\text { All } \\
\text { VWF } \\
\text { Cont } \\
\text { All } \\
\text { VWF } \\
\text { Cont }\end{array}$ & $\begin{array}{l}\mathbf{n}=12(15 \%) \\
\mathbf{n}=7(19 \%) \\
\mathbf{n}=5(14 \%) \\
\mathbf{n}=15(19 \%) \\
\mathbf{n}=10(27 \%) \\
\mathbf{n}=1(3 \%) \\
\mathbf{n}=27(34 \%)\end{array}$ \\
\hline
\end{tabular}

All = Whole material; VWF = vibration-induced white finger group; Cont = control group.

any substantial differences between the controls, whether they were exposed to vibration or not.

Most studies of VWF have been devoted to the examination of vasoconstriction, whereas damage to vasodilatative function has received less attention. Vibration can cause obstructive lesions ${ }^{11}$ and functional vasoconstrictive changes in vessels in the finger. ${ }^{12}$ Sympathetic reflex activity may also be increased among the VWF cases. ${ }^{13}$ According to Cohen et $a l,{ }^{14}$ the arteriovenous anastomosis regulated by $\beta$-adrenergic receptors plays a major part in active vasodilatation in the finger. After cooling, a diminishing of vasoconstriction (passive vasodilatative mechanism) is believed to be important as well. ${ }^{15}$ The relation between active and passive vasodilatative mechanisms, however, is not known. The data on vasodilatative disorders in VWF are negligible and ambiguous, ${ }^{16}{ }^{17}$ whereas in primary Raynaud's disease for example, the $\beta$-adrenergic mechanism can be disturbed ${ }^{1618}$ and often in previous studies the rewarming was delayed among PR cases $^{19}{ }^{20}$ as well as in the present study, indicating disorders in vasodilatative function.

In the present FSP test whole body cold exposure was mild and some of the test subjects were mild white finger cases as well. This may explain the low sensitivity $(50 \%)$ in this study. Lower room temperatures ${ }^{8}$ and body cooling with cold packs ${ }^{5}$

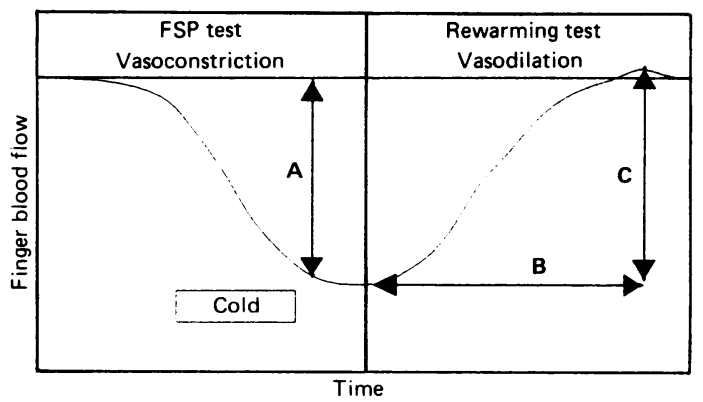

Figure 2 Schematic illustration of FSP and rewarming test presented as a function of blood flow. The FSP test measures the strength of vasoconstriction (= length of $A$ ) and rewarming rate the vasodilatative function (relation $B / C$ ). have been reported to increase the sensitivity. Sensitivity has also been low in the studies with mild VWF cases. $^{61}$ Further, the FSP test has been presumed to fail to find the cases in which the attack is caused by damage in skin circulation only or when the obstructive process is situated proximal to the test finger. ${ }^{20}$

In the recent rewarming test the rewarming rate between 10 and $90 \%$ of the maximum rewarming temperature was used as an indicator of rewarming. The possible error caused by drying the hand after immersion and waving on the skin temperature near the maximum point was then avoided. Room temperature was not a suitable cutting point in these tests, ${ }^{19}$ because in the present study the intention was to take into account the total function of the vasodilatation. The finger temperature before an immersion is not useful as a criterion for rewarming ${ }^{3}$ because if the starting temperature is low the test can give a false normal result. According to the present results both the rewarming rate and the maximum temperature of the finger rewarming were useful as indicators, but the rewarming rate fitted better to the dynamic nature of the function test.

The ROC method (fig 1) was efficient for comparing the characteristics and evaluating the values of the tests for screening and diagnosis. With our method the optimal limit of the FSP\% with regard to the anamnesis of Raynaud's phenomenon was $76 \%$ (fig 1), with a specificity of $84 \%$. Under that limit a susceptibility to vasoconstriction was enforced in workers exposed to vibration. If higher specificity for diagnosis of Raynaud's phenomenon is sought, the FSP $\%$ less than $60 \%$ can be interpreted as a diagnostic limit (specificity is then $\mathbf{9 7 \%}$ ). In earlier studies the last limit was recommended as a diagnostic limit of $\mathrm{VWF}^{610}$ or Raynaud's phenomenon. ${ }^{22}$ An evaluation with the ROC method showed that the FSP test was suitable for diagnosis of Raynaud's phenomenon (high specificity) but the sensitivity was too low for screening. The test cannot differentiate VWF cases from other Raynaud's cases, however. ${ }^{20}{ }^{23}$ Promising attempts have been made recently to improve the specificity of the test. ${ }^{2024}$

The optimal limit of the rewarming rate $\left(1 \cdot 15^{\circ} \mathrm{C} /\right.$ 
min) with regard to the anamnesis of Raynaud's phenomenon had a specificity and a sensitivity of about $70 \%$ (fig 1). For screening purposes the limit $1.94^{\circ} \mathrm{C} / \mathrm{min}$ had a more satisfactory sensitivity $(83 \%)$, but specificity was only $38 \%$. Hence, over $60 \%$ of healthy subjects would not pass the test and should be examined further. In other studies the sensitivity and the specificity have been for example, 39 and $85 \%,{ }^{3} 60$ and $92 \%,{ }^{2}$ and 79 and $50 \%{ }^{25}$ with regard to the anamnesis of VWF. According to the preceding values the rewarming test seems to be useful for screening in the study of Ishitake et al only. ${ }^{25}$ According to our study, however, the rewarming test is not recommended for screening of VWF because it did not measure the amount of vasoconstriction and no evidence exists for VWF having biological connections with passive or active vasodilatative mechanisms. Also the rewarming test failed to find many strongly vasoconstrictive VWF cases (measured with the FSP test). The results showed that the rewarming test could be useful for the screening of primary Raynaud's cases and possibly for the screening of vasodilatative disorders.

Two different theories could explain why rewarming has often been reported to be delayed in VWF groups. Firstly, when vibration causes organic damage in smooth muscles of arteries, it could also disturb a release of vasoconstriction caused by noradrenaline. This mechanism fits with the VWF group, which had pathological findings in both tests. The second possibility is that exposure to vibration causes Raynaud's phenomenon to appear readily in the workers who have disorders in vasodilatative mechanisms as well as in primary Raynaud's disease and this type of sensitive worker could accumulate in the VWF group. Both hypotheses could also explain why the rewarming test has not been useful for testing individual vibration workers.

1 Matoba T, Sakurai T. Physiological methods used in Japan for the diagnosis of suspected hand-arm vibration syndrome. Scand J Work Environ Health 1987;13:334-6.

2 Bovenzi M. Finger thermometry in the assessment of subjects with vibration-induced white finger. Scand $J W$ ork Environ Health 1987;13:348-51.

3 Pelmear PL, Roos J, Leong D, Wong L. Cold provocation test results from a 1985 survey of hard-rock miners in Ontario. Scand J Work Environ Health 1987;13:343-7.

4 Hack M, Boillat M-A, Schweizer C, Lob M. Assessment of vibration induced white finger: reliability and validity of two tests. Br J Ind Med 1986;43:284-7.
5 Olsen N. Diagnostic tests in Raynaud's phenomena in workers exposed to vibration: a comparative study. $\mathrm{Br} J$ Ind $\mathrm{Med}$ 1988;45:426-30.

6 Ekenvall L, Lindblad L-E. Vibration white finger and digital systolic pressure during cooling. BrJ Ind Med 1986;43:280-3.

7 Nielsen SL, Lassen NA. Measurement of digital blood pressure after local cooling. J Appl Physiol 1977;43:907-10.

8 Ekenvall L, Lindblad L-E. Digital blood pressure after local cooling as a diagnostic tool in traumatic vasospastic disease. Br J Ind Med 1982;39:388-91.

9 Sackett DL, Haynes RB, Tugwell P. Clinical epidemiology. A basic science for clinical medicine. Boston: Little, Brown and $\mathrm{Co}$, 1985.

10 Bovenzi M. Finger systolic pressure during local cooling in normal subjects aged 20 to 60 years: reference values for assessment of digital vasospasm in Raynaud's phenomenon of occupational origin. Int Arch Occup Environ Health 1988;61:179-81.

11 Takeuchi T, Futatsuka M, Imanishi H, Yamada S. Pathological changes observed in the finger biopsy of patients with vibration-induced white finger. Scand $J$ Work Environ Health 1986;12:280-3.

12 Azuma T, Ohashi T. Pathophysiology of vibration-induced white finger: Ethiological considerations and proposals for the prevention. In: Brammer AJ, Taylor W, ed. Vibration effects on the hand and arm in industry. New York: John Wiley \& Sons, 1982:31-8.

13 Pyykkö I, Hyvärinen J, Färkkilä $M$. Studies on the etiological mechanism of the vasospastic component of the vibration syndrome. In: Brammer AJ, Taylor W, ed. Vibration effects on the hand and arm in industry. New York: John Wiley \& Sons, 1982:13-24.

14 Cohen RA, Coffman JD. Beta-adrenergic vasodilator mechanism in the finger. Circ Res 1981;49:1196-201.

15 Zelis R. Mechanisms of vasodilation. Am J Med 1983;74:3-12.

16 Magos L, Okos G. Cold dilatation and Raynaud's phenomenon. Arch Environ Health 1969;7:402-10.

17 Wallin G. Hudblockarlens känslighet för sympatisk nervstimulering hos friska och patienter med vibrations utlosta circulations besvär. Arbetarskyddsfondens sammanfattningar No 938 ASFs Pnr 82-0053 vibrationer 33, 1986.

18 Brotzu G, Falchi S, Montisci R, Petruzzo P. Beta-blockers: A new therapeutic approach to Raynaud's disease. Microvasc Res 1987;33:283-8.

19 Welsh CL. Digital rewarming time in the assessment of vibration-induced white finger. Scand J Work Environ Health 1986;12:249-50.

20 Arneklo-Nobin B, Johansen K, Sjöberg T. The objective diagnosis of vibration-induced vascular injury. Scand JWork Environ Health 1987;13:337-42.

21 Pyykkö I, Färkkilä M, Korhonen O, Starck J, Jäntti V. Cold provocation tests in the evaluation of vibration-induced white finger. Scand J Work Environ Health 1986;12:254-8.

22 Olsen N, Nielsen SL, Voss P. Cold response of digital arteries in chain saw operators. $\mathrm{Br} J$ Ind $\mathrm{Med} 1981 ; 38: 82-8$.

23 Ekenvall L, Lindblad LE, Bevegard S, Etzell BM. High vascular tone but no obliterative lesions in vibration white fingers. $\mathrm{Am} \mathrm{J}$ Ind Med 1987;12:47-54.

24 Olsen N, Petring OU. Vibration elicited vasoconstrictor reflex in Raynaud's phenomena. Br J Ind Med 1988;45:415-9.

25 Ishitake $T$, Ohkubo A, Oki M, Suenaga T, Sakurai T, Matoba T. A simplified cold water immersion test for peripheral circulatory function. In: Okada $A$, Taylor $W$, Dupuis $H$, ed. Hand-arm vibration. Kanazawa: Kyoei Press Co, 1990:215-9.

Accepted 26 November 1990 